Technical Paper

\title{
Crankshaft Design Optimization to Improve Dynamic Balancing and Fatigue Strength
}

\author{
Vijaykumar Khasnis ${ }^{1)}$ Manoj Ukhande ${ }^{2)}$ Girish Tilekar $^{3)}$ Rajesh Mane $^{4)}$ Girish Shegavi ${ }^{5)}$
}

1)-5) R\&D CDFD Engineering, Bharat Forge Ltd., Mundhwa, Pune, 411036, India

(Email: manojukhande@bharatforge.com)

Received on June 26, 2013

Presented at the JSAE Annual Congress on May 24, 2013

\begin{abstract}
This study demonstrates crankshaft counterweight profile optimization to achieve better dynamic balancing. Balancing simulation was carried to predict initial unbalance. During balancing of actual crankshaft, the position of unbalance is sometimes shifted due to machining stock distribution towards non-favorable direction resulting into more number of balancing holes, thus productivity loss. To reduce this, counterweight profile optimized. After balancing, bending fatigue test carried out. Crankshaft exhibited pre-mature failure at unusual location. To determine the reason of failure, stress analysis was performed using FEA. Design enhancement solution proposed to reduce the stresses \& subsequently enhance bending fatigue strength.
\end{abstract}

KEYWORDS: vehicle development, computer aided engineering, design optimization, materials, iron and steel materials, engine components, Fatigue, crankshaft balancing [B2]

\section{INTRODUCTION}

Crankshaft is the vital part of an engine. Crankshaft converts reciprocating motion of piston into rotational motion. Crankshaft having complex geometry, experiences large number of load cycles during its service life therefore, balancing, fatigue performance and durability are key considerations in crankshaft design ${ }^{(1)}$. During service life, crankshaft operates under high forces resulting from gas combustion and inertia forces. These forces acting on the crankshaft causes two types of fluctuating loadings i.e. torsional load and bending load. Hence crankshaft requires high torsional and bending fatigue strength and better balancing characteristics to survive safely during its service life (2). Designers of modern internal combustion engines are facing the challenge of reducing the environmental pollution to meet stringent pollution control regulations all over the world. Environmental pollution can be reduced through improving engine efficiency. In addition, the designers are also required to reduce the weight and overall dimensions of the engine to make them more and more compact to increase power and RPM. Development of lightweight, compact, high pressure and high RPM engine demands a crankshaft with better dynamic balancing characteristics with high fatigue strength. This results into lower $\mathrm{NVH}$ levels, reductions in bearing and engine block loads along with improved engine performance ${ }^{(3)}$.

There are closed die forging and casting crankshafts for an automobile engine, and die forging is mainly used for engine that needs the high strength or rigidity. However, in recent years, the forces to act on crankshaft become higher, because the high performance required for engines. When all balance weights are uniformly small, the main bearings are damaged by the increase of bearing load and engine vibrations (4). Hence crankshaft counterweight configuration plays significant role in crankshaft balancing, bearing and engine block life. Crankshaft balancing is the term used to describe changes made in the counterweights (balance weights) to compensate for the weights of the moving components including the crankshaft and the components attached to it (connecting rods, pistons etc.). The counterweights are cast or forged in place when the crankshaft is formed, and the balancing is required to remove some amount of material from the counterweights (usually by drilling holes) until the amount of unbalance is within acceptable limit.

Unbalance is defined as the unequal distribution of mass within a rotor about its rotating centerline. The amount of unbalance in rotating body is normally expressed as the product of the residual unbalance mass and its distance from center line. Therefore a general unit for expressing unbalance is g.m ${ }^{(5)}$. The out of balance forces are centrifugal forces. These forces pull the crank towards the bearing as it rotates. This causes the premature bearing wear, loss of power and damaging vibrations. The international standard organization defines unbalance as, "That condition which exists in a rotor when vibratory force or motion is imparted to its bearings as a result of centrifugal forces". The rotating centerline being defined as the axis about which the rotor would rotate if not constrained by its bearings. (Also called the Principle Inertia Axis) as shown in Figure 1. The geometric centerline is being the physical centerline of the rotor. When the two centerlines are coincident, then the rotor will be in a state of balance. When they are apart, the rotor will be unbalanced. During the balancing process when the unbalance has been identified and quantified the correction can be done by either adding or removing the material from rotating element. The ultimate aim being to reduce the uneven mass distribution so that the centrifugal forces and hence the vibrations induced in the supporting structures are at an acceptable level ${ }^{(6)}$.

The amount of force created by unbalance depends on speed of rotation and the amount of unbalance. Force generated by the unbalance can be calculated by the formula,

$$
F=m r \omega^{2}
$$

Where $\mathrm{F}$ is centrifugal force, $\mathrm{m}$ is mass; $\mathrm{r}$ is distance of center of gravity (CG) from axis of rotation and $\omega$ is angular speed. 


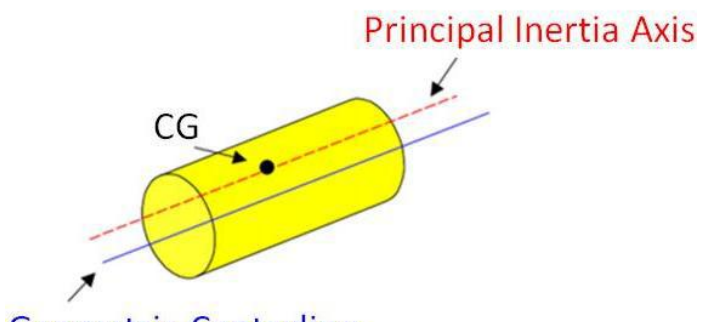

Geometric Centerline

Fig.1 Rotor Shaft

Crankshaft balancing is the important part of today's engine development activity. In this study balancing analysis was carried out by using in-house developed balancing software and its initial unbalance mass and position was predicted. After forging and machining the crankshaft, the actual balancing was carried out using balancing machine. The results had shown that, the actual position of unbalance was deviated from predicted due to machining stock distribution in non-favorable direction during forging process. The actual unbalance position was in such a direction that, there was complex counterweight profile available for removal of material. Due to this, the balancing of such crankshafts was difficult. To correct this, counterweight profile was optimized in such a way that, position of initial unbalance lies at the center of counterweights. With this optimized design the crankshafts were produced and the results shown good correlation between the predicted and actual position of unbalance. With this unbalance position the balancing was achieved with maximum 6 numbers of holes which is within target limit.

\section{CRANKSHAFT BALANCING}

\subsection{Crankshaft Balancing Simulation (Initial Design)}

3D CAD model of the 6 cylinder crankshaft was created in Unigraphics NX7. Balancing analysis was carried out by using Dual plane method. One plane is passing through center of main journal 1 and normal to the axis of crankshaft called as tail side unbalance plane. Other plane is passing through center of main journal 7 and normal to the axis of crankshafts called as flange side unbalance plane. These tail side and flange side planes are called as unbalance measurement planes as shown in Figure 2.

Amount of initial unbalance measured on flange side and tail side is shown in Figure 3 and Table 1. To remove the initial unbalance on flange and tail side, depending on unbalance angle, the holes are drilled on respective counterweights. Total 6 numbers of holes are drilled to reduce the unbalance up to the acceptance limit $2 \mathrm{~g}$.

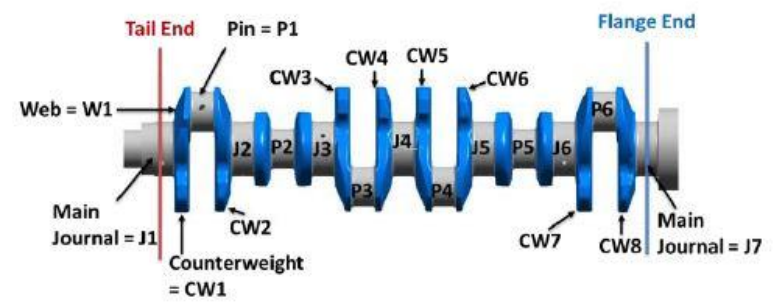

Fig. 2 Unbalance measurement plane

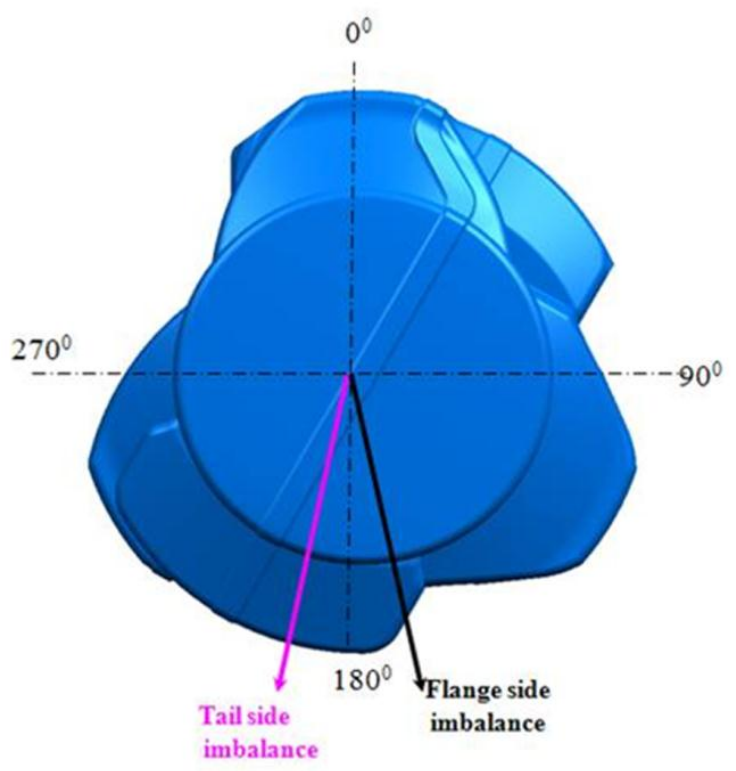

Fig. 3 Initial Design - initial unbalance (Simulation)

Table 1 Initial design unbalance data (Simulation)

\begin{tabular}{|c|c|c|c|c|}
\hline \multirow{2}{*}{} & \multicolumn{2}{|c|}{ Tail Side } & \multicolumn{2}{c|}{ Flange Side } \\
\cline { 2 - 5 } & $\begin{array}{c}\text { Unbalance } \\
(\mathrm{g})\end{array}$ & $\begin{array}{c}\text { Angle } \\
(\mathrm{Deg})\end{array}$ & $\begin{array}{c}\text { Unbalance } \\
(\mathrm{g})\end{array}$ & $\begin{array}{c}\text { Angle } \\
(\text { Deg})\end{array}$ \\
\hline $\begin{array}{c}\text { Initial } \\
\text { Design }\end{array}$ & 50 & 188 & 62 & 170 \\
\hline
\end{tabular}

\subsection{Crankshaft Actual Balancing (Initial Design)}

After forging and machining the crankshaft, balancing was carried out using balancing machine. Due to uneven stock distribution during forging process, it was observed that, tail side initial unbalance mass was up to $60 \mathrm{~g}$ and angle was not at center of end counter weight number 1 and 2 (towards P2 side) as shown in Figure 4 and Table 2.

Table 2 Initial design unbalance data (Actual)

\begin{tabular}{|c|c|c|c|c|}
\hline \multirow{2}{*}{} & \multicolumn{2}{|c|}{ Tail Side } & \multicolumn{2}{c|}{ Flange Side } \\
\cline { 2 - 5 } & $\begin{array}{c}\text { Unbalance } \\
(\mathrm{g})\end{array}$ & $\begin{array}{c}\text { Angle } \\
(\mathrm{Deg})\end{array}$ & $\begin{array}{c}\text { Unbalance } \\
(\mathrm{g})\end{array}$ & $\begin{array}{c}\text { Angle } \\
(\mathrm{Deg})\end{array}$ \\
\hline $\begin{array}{c}\text { Initial } \\
\text { Design }\end{array}$ & 60 & 135 & 75 & 140 \\
\hline
\end{tabular}

Also flange side initial unbalance mass was up to $75 \mathrm{~g}$ and angle was not at the center of end counter weight number 7 and 8 (towards P5 side) as shown in Figure 5. Due to this, balancing was achieved on some parts with more number of balancing holes resulting into higher balancing cycle time. 


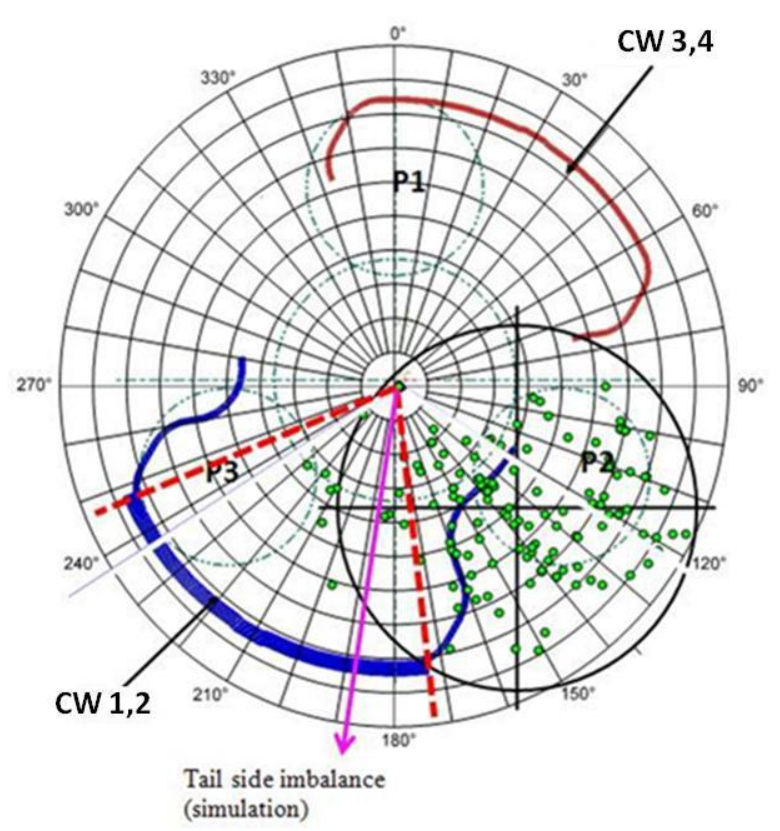

Fig. 4 Initial design -Tail side unbalance (Actual)

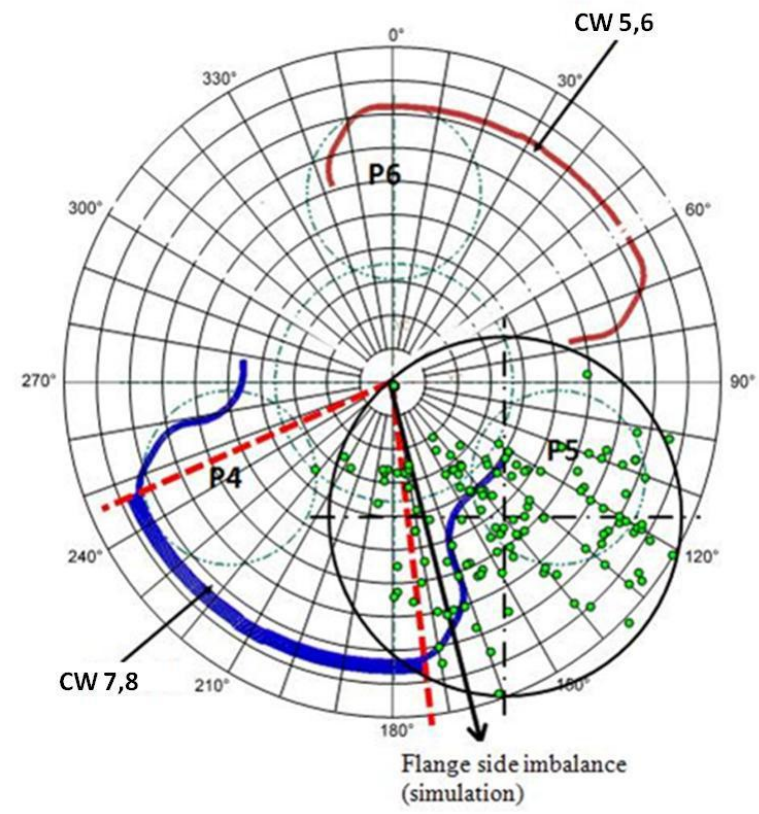

Fig. 5 Initial design Flange side unbalance (Actual)

In Figure 4, circle consists of scatter points shows the unbalance positions on actual crankshafts. Each point corresponds to one crankshaft. In scatter circle region, small portion of counterweight available to drill the holes and to achieve balancing condition. Similar results observed on flange side as shown in Figure 5. To avoid this situation, counterweight profile reengineering was carried out. Radial direction in Figure 4, 5, 10 and 11 shows the position of imbalance mass measured in various crankshafts.

\subsection{Crankshaft Balancing Simulation (Re-engineered Design)}

In re-engineered design, counterweight profile was optimized as shown in Figure 6, in such way that, the position of initial unbalance lies at the center of counterweights which is considered as favorable direction for better balancing condition. The results are as shown in Table 3.

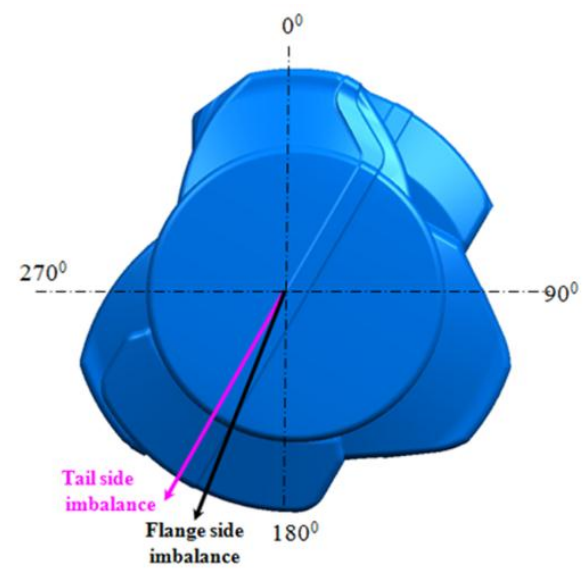

Fig. 6 Re-engineered design - flange side unbalance (simulation)

Table 3 Re-engineered design balancing data (Simulation)

\begin{tabular}{|l|c|c|c|c|}
\hline \multirow{2}{*}{} & \multicolumn{2}{|c|}{ Tail Side } & \multicolumn{2}{c|}{ Flange Side } \\
\cline { 2 - 5 } & $\begin{array}{c}\text { Unbalance } \\
(\mathrm{g})\end{array}$ & $\begin{array}{c}\text { Angle } \\
(\text { Deg })\end{array}$ & $\begin{array}{c}\text { Unbalance } \\
(\mathrm{g})\end{array}$ & $\begin{array}{c}\text { Angle } \\
(\mathrm{Deg})\end{array}$ \\
\hline $\begin{array}{l}\text { Re- engineered } \\
\text { Design }\end{array}$ & 40 & 220 & 50 & 210 \\
\hline
\end{tabular}

The comparison between initial and optimized counterweight profile is shown in Figure 7.

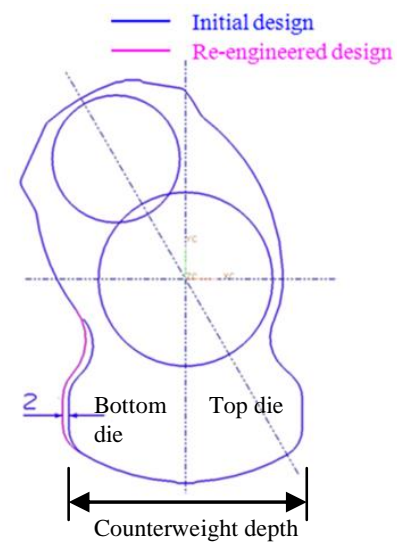

Fig. 7 Counterweight profile comparison

Figure 7 shows that in re-engineered design counterweight depth increased by $2 \mathrm{~mm}$ and thickness increased by $0.5 \mathrm{~mm}$ in bottom die portion of counterweight. In this modification, the change in counterweight profile is within specified envelope of an engine.

\subsubsection{Re-Engineered Design - Forge ability Validation}

With modified counterweight profile, it is necessary to ensure forging feasibility of crankshaft. Metal flow simulation was carried out by using high end software Forge 2007. Forging die models were generated by using Unigraphics 3D modeling software. Die models were meshed in Hypermesh. Die and billet mesh models imported in Forge software. Process parameters such as friction, temperature, lubricant were defined as per actual working conditions. Press parameters such as $R / L$ ratio $(R$ is crank radius and $\mathrm{L}$ is pitman arm length), maximum available energy were defined. The analysis completed with high speed 
supercomputing cluster. Crankshaft forging simulation was carried out in successive steps i.e. reduce roll, blocker and finisher. Reduce roll was optimized as per metal requirements of die cavities. Output deformed shape of each operation used as input for subsequent operation. During analysis, metal fill up was analyzed as shown in Figure 8.

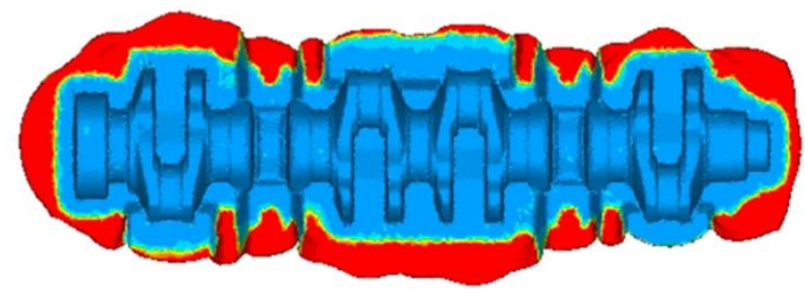

Fig. 8 Re-engineered crankshaft design metal flow analysis

By using virtual technology forging feasibility of Re-engineered design was ensured before actual shop floor trial which reduces considerably product development time, saves tooling cost. By using these forging dies, the components were produced.

\subsubsection{Bending Deflection and Bearing Load Evaluation}

When a crankshaft rotates with given rpm, generated centrifugal force causes bending deflection in crankshaft. Counterweight profile has significant effect on bending deflection and bearing load of crankshaft. This analysis was carried out by using ANSYS. In FEA for evaluation of bending deflection, bearings were mounted on first and last journal and crankshaft rotated with 2500 RPM. Due to centrifugal forces, bending deflection occurs in crankshaft. Bending deflection for modified design is shown in Figure 9.

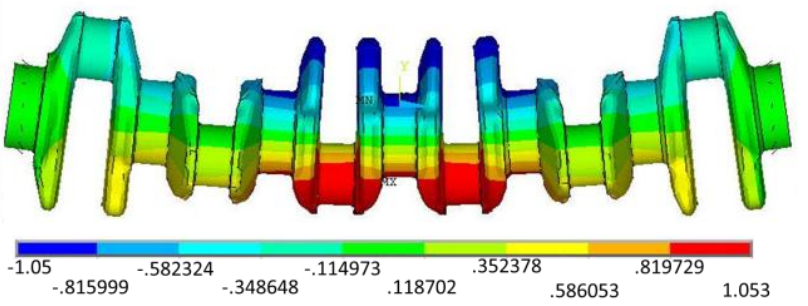

Fig. 9 Crankshaft Bending Deflection (mm)

To evaluate bearing load under inertia forces, bearings were mounted on each journal and crankshaft rotated with 2500 RPM Bending deflection and bearing load comparison for initial design and Re-engineered design is shown in Table 4.

Table 4 Initial Design Vs Re-engineered Design

\begin{tabular}{|c|c|c|}
\hline Parameters & Initial design & Optimized design \\
\hline Deflection $(\mathrm{mm})$ & 1.07 & 1.05 \\
\hline Bearing load $(\mathrm{N})$ & 1143 & 1087 \\
\hline
\end{tabular}

Table 4 shows that, in re-engineered design, bending deflection and bearing load are in-line with initial design.

\subsection{Crankshaft Actual Balancing (Reengineered Design)}

With Re-engineered design, crankshafts were produced and balancing was carried out. The unbalance data for various crankshafts is shown in Figure 10 and Figure 11 and Table 5.
Table 5 Reengineered design balancing data (Actual)

\begin{tabular}{|l|c|c|c|c|}
\hline \multirow{2}{*}{} & \multicolumn{2}{|c|}{ Tail Side } & \multicolumn{2}{c|}{ Flange Side } \\
\cline { 2 - 5 } & $\begin{array}{c}\text { Unbalance } \\
(\mathrm{g})\end{array}$ & $\begin{array}{c}\text { Angle } \\
(\mathrm{Deg})\end{array}$ & $\begin{array}{c}\text { Unbalance } \\
(\mathrm{g})\end{array}$ & $\begin{array}{c}\text { Angle } \\
(\mathrm{Deg})\end{array}$ \\
\hline $\begin{array}{l}\text { Re- engineered } \\
\text { Design }\end{array}$ & 45 & 210 & 40 & 215 \\
\hline
\end{tabular}

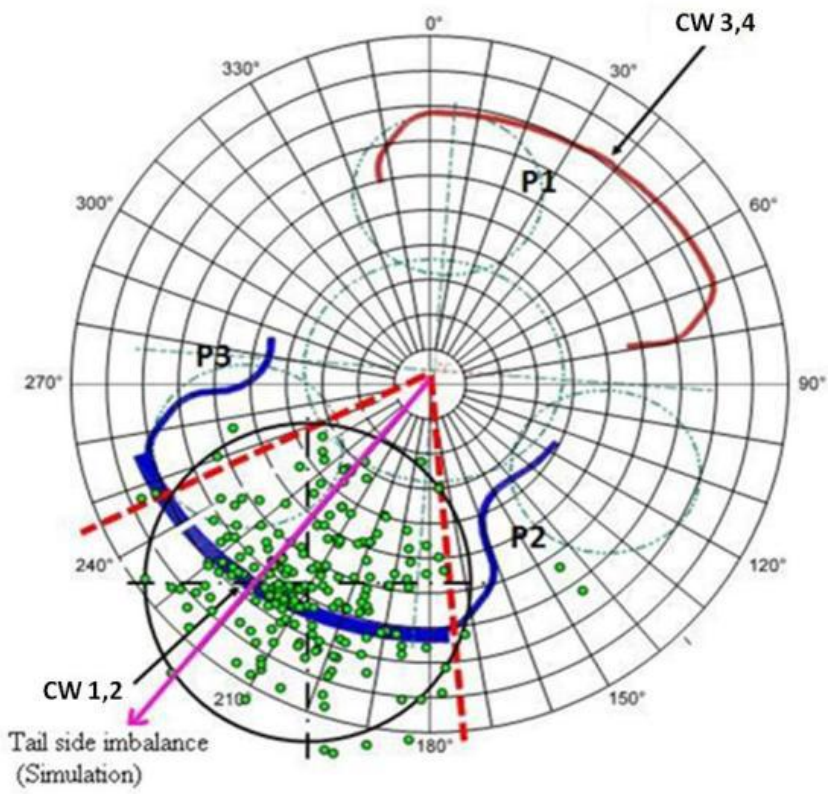

Fig. 10 Re-engineered design - Tail side unbalance (Actual)

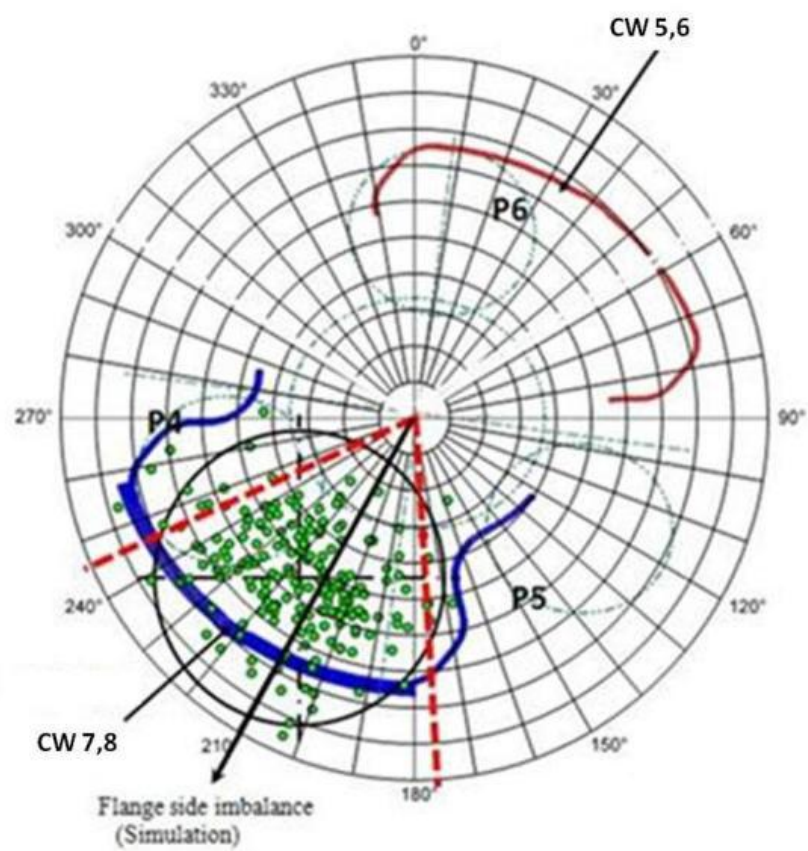

Fig. 11 Re-engineered design - Flange side unbalance (Actual)

In re-engineered design, the unbalance mass has been reduced in tail side, from $60 \mathrm{~g}$ to $45 \mathrm{~g}$ and initial unbalance angle is near center of end counter weight and in flange side, initial unbalance reduced from $75 \mathrm{~g}$ to $40 \mathrm{~g}$ and angle is near center of end counter weight. Most of the jobs were balanced with balancing holes less than 5 . 


\section{CRANKSHAFT FATIGUE STRENGTH VALIDATION}

\subsection{Physical Test Validation}

After balancing, one of the important stage in the product development is the fatigue testing to ensure the required bending fatigue strength of crankshaft. Fatigue strength is the mean stress level at which component have $50 \%$ probability of failure and $50 \%$ pass. The test was carried out according to staircase method by inducing expected stress level at pin fillet. First specimen was tested at a stress level close to expected endurance limit of crankshaft until it either fails or runs out at the expected life (in this case it is $5 \mathrm{~m}$ cycles). If the specimen fails at that stress level, the same is reduced by a preselected step and the new specimen is tested at new stress level. If the specimen passes the required life at a particular stress level, the same is increased by a preselected step and the second specimen is tested at this new stress level. In this way 10 specimens were tested. Using statistical approach fatigue strength is evaluated.

According to the acceptance criteria and as per the design requirement, crankshaft has to resists $5 \times 106$ cycles without failure so it was tested for the said number of cycles. But during the fatigue testing, crack initiation occurred before this load cycle limit. It was observed that, premature crack was observed in the abnormal location i.e. pin bevel after 1 million cycles as shown in Figure 12.

However critical locations on the crankshaft geometry are all located on the fillet areas because of high stress gradients in these locations which result in high stress concentration factors (7) Hence the expected failure region in bending fatigue test in most cases in pin fillet and in some cases in journal fillet.

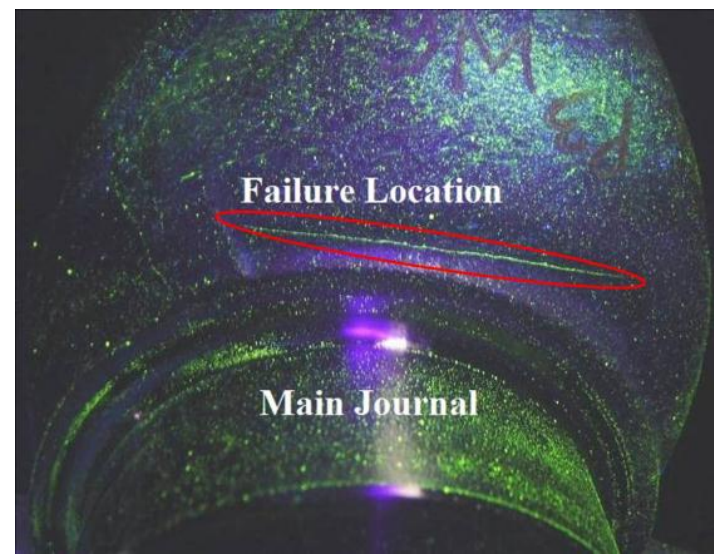

Fig. 12 Crankshaft Failure Location

The failure analysis was carried out by using the following stages ${ }^{(8)}$ : 1. Collection of background data, 2. Preliminary examination of failed part, 3. Microscopic and Macroscopic examination and analysis, 4. Chemical analysis and 5. Testing under simulated service conditions. It is important to remember that a metallurgical failure analysis is in many cases not enough to determine the root causes of a failure ${ }^{(8)}$.

Metallurgical analysis shown that, chemical composition of the crankshaft material, in general, is within the range of the technical demand and no obvious forging or machining defects were found. Hardness was also found within specified limit. Hence Metallurgical investigation revealed no abnormalities in the material.
The start of fatigue failure is a strictly local process and it is also one that depends on the dynamics of the system. This is precisely why FEA is important in this discipline. By using FEA an analyst can choose any location within a model and concentrate attention on it. Using FEA gives tighter control over the move from general geometry and loading to local parameters ${ }^{(9)}$. To predict the reason of the premature failure, a detailed solid model (single throw) of the crankshaft was prepared in Unigraphics commercial software. By using this model, Finite Element Model was prepared. The stress analysis was performed by using ANSYS V12 commercial FEA software.

\subsection{Finite Element Analysis and Results}

FEA was carried out to investigate reason of failure at bevel region. A virtual setup was created in HPERMESH V11 environment as shown in Figure 13. The model was meshed with 10 node tetrahedron elements. Nylon ropes were represented by spring element. Bending mode shape and respective frequency was obtained from modal analysis. This frequency was used as an input for the harmonic analysis. Harmonic analysis was processed with same "g" level as used in physical test setup. This g level is equivalent to $750 \mathrm{MPa}$ pin fillet stress. Stress and strains were measured at same locations as that of strain gauge location in physical setup. The material properties used for analysis are shown in Table 6 .

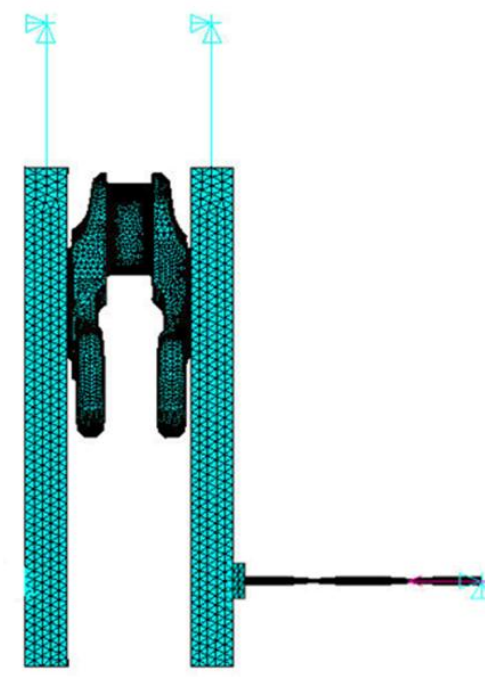

Fig. 13 FEA Model of Bending Test

Table 6 Mechanical Properties used for Analysis

\begin{tabular}{|c|c|}
\hline UTS & $750 \mathrm{MPa}$ \\
\hline Modulus of elasticity & $210000 \mathrm{MPa}$ \\
\hline Poisson's ratio & 0.3 \\
\hline
\end{tabular}

FEA results are shown in Figure 14. This figure shows principal stress distribution in critical areas of crankshaft. 


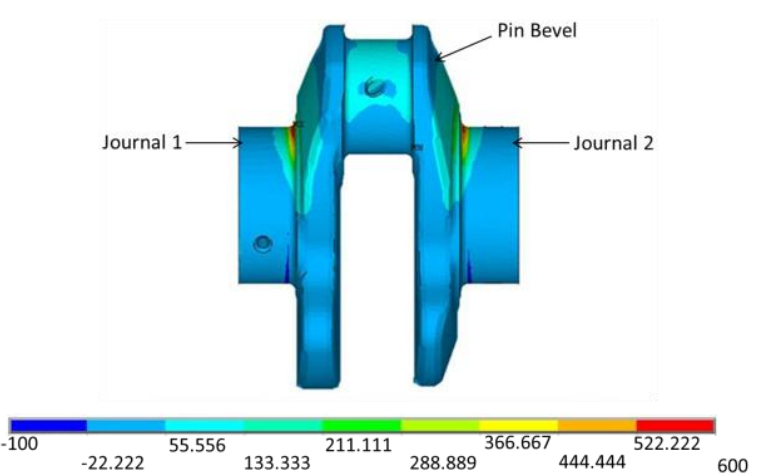

Fig. 14 Bending Stress (MPa) Analysis

The stresses at journal fillet by FEA and physical test shows good agreement as shown in Table 7. FEA results shown higher stresses at failed location. FEA high stress location and premature fatigue failure location (bevel region) matches as shown in Figure 15.

Table 7 Comparison between FEA and physical test results

\begin{tabular}{|c|c|c|}
\hline Description & Frequency(Hz) & Journal Fillet(MPa) \\
\hline FEA & 68 & 600 \\
\hline Testing & 70 & 573 \\
\hline$\%$ Variation & 2.8 & 4.7 \\
\hline
\end{tabular}
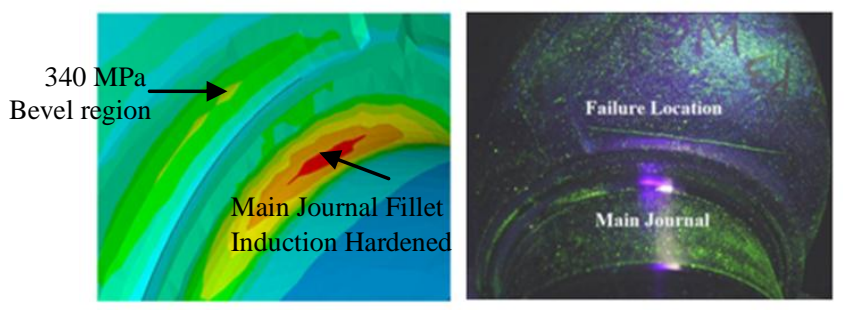

Fig. 15 Comparison of FEA and Actual Test Results

\subsection{Fatigue Factor of Safety Evaluation}

Fatigue analysis was performed as the crankshaft was loaded with dynamic forces during the service. Based on rotating bending fatigue test of specimen the evaluated Endurance strength (Se) is $50 \%$ of Ultimate tensile strength $\left(S_{u l t}\right)$ of material. By considering the effect of process and geometrical parameters, endurance strength reduces to $40 \%$ of ultimate tensile strength. Hence the stress life endurance limit $S_{e}$ is given as,

$$
S_{e}=0.4 S_{u l t}
$$

Where $S_{u l t}$ is the ultimate strength of material which is $750 \mathrm{MPa}$

Hence from equation (2), endurance strength of material is 300 MPa. ${ }^{\text {st }}$ Principal stress obtained from FEA are utilized in fatigue life calculations. Since the loading has a sinusoidal fluctuating characteristic (mean stress $=0$ ), modified Goodman approach given as ${ }^{(10)}$

$$
\frac{\sigma_{a}}{S_{e}}+\frac{\sigma_{m}}{S_{u l t}}=\frac{1}{n}
$$

Where,

$$
\sigma_{a}=\frac{\sigma_{\max }-\sigma_{\min }}{2}
$$

And

$$
\sigma_{m}=\frac{\sigma_{\max +} \sigma_{\min }}{2}
$$

Amplitude stress at bevel region is $340 \mathrm{MPa}$ and loading condition is $\mathrm{R}=-1$ (mean stress $=0$ ) hence evaluated fatigue factor of safety using equation (3) is 0.88 . This means that at bevel region fatigue crack can initiate before the required number of cycles. To avoid fatigue failure at bevel region, design modified as shown in Figure 16.
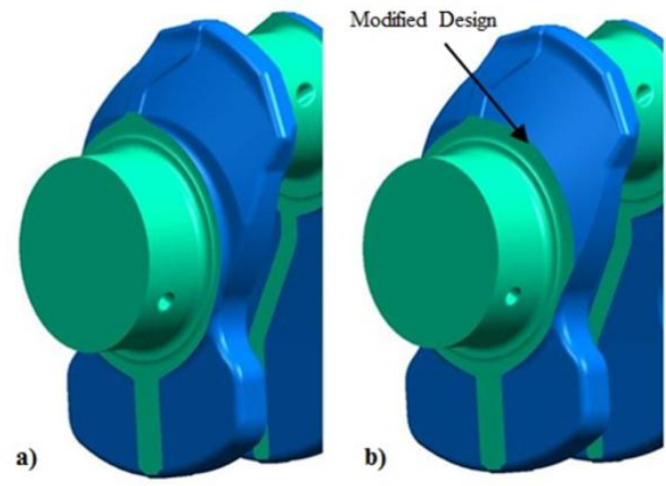

Fig. 16 Initial Design Vs R-engineered design

In Modified geometry $15 \mathrm{~g}$ of material added to bevel profile. Re-engineered crankshaft design was verified by FEA for bending stress analysis. Stresses in bevel region reduced by $35 \%$ as compared to initial design as shown in Figure 17. Hence Fatigue factor of safety in modified design comes out to 1.4. This design change was implemented in manufacturing and re-engineered crankshaft tested in lab which meets the bending fatigue strength specifications. Failure in pin bevel region avoided due to local geometry modification.

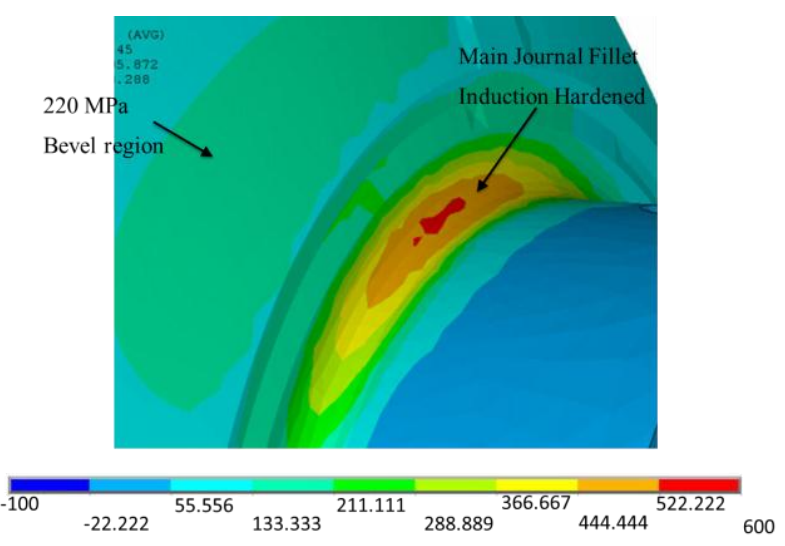

Fig. 17 Bending Stress Analysis at Pin Bevel

A total of 10 single throw specimens made from re-engineered crankshaft designs were tested using staircase method and fatigue strength was evaluated. Fatigue strength of re-engineered 
crankshaft was increased by $10 \%$ as compared to initial design as shown in Figure 18.

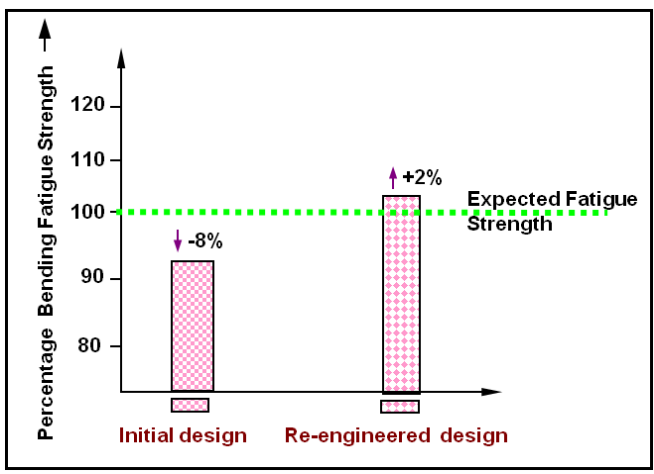

Fig. 18 Bending Fatigue Strength

\section{CONCLUSION}

1. This work shows the sensitivity of counterweight profile for crankshaft balancing. Slight modification in profile affects largely the dynamic balancing characteristics of crankshaft.

2. Counterweight profile configuration has to be designed in such a way that, position of unbalance will appear near the center of counterweight profile.

3. Under Load ratio $\mathrm{R}=-1$ (mean stress $=0$ ), pin bevel region near main journal fillet is critical; hence stress riser geometry must be avoided in pin bevel region.

4. In re-engineered design, fatigue strength enhanced by $10 \%$. Hence exceeded the fatigue strength target set by engine manufacturer.

5. Perfectly designed components will last their intended lifetime and will help to save resources, thus improving the efficiency of manufacturing companies.

\section{REFERENCES}

(1) Anderson, D., Lewis, K., "Detailed Study of Crankshafts Demonstrates Superior Fatigue Performance and Durability of Forged Steel Over Competing Material", FIERF, \& AISI, Detroit, USA, pp.1-2. (2007)

(2) Rajesh, Mane; Manoj, Ukhande. "Crankshaft Fatigue Test Validation using CAE", Asia Forge, International Forging Conference, Delhi, pp. 1-2. (2008)

(3) Manoj, Ukhande; Rajesh, Mane and Girish, Shegavi. "Optimization of Crankshaft Torsional Rigidity for Fatigue Strength Improvement Using CAE", SAE 2012 World congress, Paper No.2012-01-0404, Detroit, Michigan, USA,

(4) Takahiro, Fujimoto; Miyuki, Yamamoto; Kazuo, Okamura and Yasuo, Hida. "Development of Crankshaft Configuration Design", SAE 2001 World Congress, SAE Technical Paper No.2001-01-1008, Detroit, Michigan, USA,

(5) S. Smith "The Balancing Act: Balance the Design, or Design for Balance?" Vibration Free, Unit 18, Green Farm, Fritwell, Bicester, Oxon, pp. 1-3.
(6) J. Lyons, "Primer on Dynamic Balancing - Causes, Corrections and Consequences", Main Tech south, pp. 1-3. (1998)

(7) Farzin, Montazersadgh; Ali, Fatemi. "Dynamic Load and Stress Analysis of Crankshaft", SAE World Congress and Exhibition, Technical Paper No.2007-01-0258, Detroit, Michigan USA,

(8) Moore, D.; Packer, K., Jones, A., and Carlson, D., "Crankshaft Failure and Why it May Happen Again", ASM International, PFANF8, pp. 1-2. (2001)

(9) Beden, S.; Abdullah, S.; Ariffin, A., Asady N., Rahman, M., " Fatigue Life Assessment of Different Steel-Based Shell Materials Under Variable Amplitude Loading", European Journal of Scientific Research, ISSN 1450216X Vol.29 No.1, pp.161-162. (2009)

(10) Shigley, Joseph; Charles, Mischke; Richard, Budynas; "Mechanical engineering design", $7^{\text {th }}$ Edition, McGrawHill Publication, USA, pp 345-350. (2003)

\section{CONTACT INFORMATION}

1. Mr. Vijaykumar Khasnis

Associate Vice President, R\&D CDFD Engg.

Bharat Forge Ltd.

Mundhwa, Pune 411 036, India.

Tel.: (020) 67042362

Email: VKhasnis@bharatforge.com

2. Mr. Manoj Ukhande

Manager, R\&D CDFD Engg.

Fatigue Testing Lab/ CAE

Bharat Forge Ltd.

Mundhwa, Pune 411 036, India.

Tel.: (020) 67042672

Email: manojukhande@bharatforge.com

3. Mr. Girish Tilekar

Assistant Manager, R\&D CDFD Engg.

Bharat Forge Ltd.

Mundhwa, Pune 411 036, India.

Tel.: (020)6704 2389

Email: girishtilekar@bharatforge.com

4. Mr. Girish Shegavi

Deputy Manager, R\&D CDFD Engg.

Fatigue Testing Lab/ CAE

Bharat Forge Ltd.

Mundhwa, Pune 411 036, India.

Tel.: (020) 67042673

Email: girishshegavi@bharatforge.com

5. Mr. Rajesh Mane

Manger, R\&D CDFD Engg.

Fatigue Testing Lab/ CAE

Bharat Forge Ltd.

Mundhwa, Pune 411 036, India.

Tel.: (020) 67042672

Email: rajeshmane@bharatforge.com

\section{ACKNOWLEDGMENT}

We would like to thank Mr. Shyam Takale, Executive Vice President and Director, Engineering, Bharat Forge Ltd, Pune, India and Mr. B. Mukherjee, Director, Product Engineering, Bharat Forge Ltd. to encourage us for carrying out this exercise. 
Our special thanks to Mr. S. Bhattacharji and Mr. Sangameshwar Pawar, AVP's from Bharat Forge Ltd. Pune and Mrs. Swati Athavale, Engineering Consultant (NVH / CAE) for their kind support and guidance.

Thanks to our departmental colleagues and others who helped us directly or indirectly.

APPENDIX

\begin{tabular}{|c|c|}
\hline Symbol & Description \\
\hline$F$ & Force \\
\hline$m$ & Mass \\
\hline$r$ & Distance from axis of rotation \\
\hline$\omega$ & Angular Speed \\
\hline$\sigma_{a}$ & Stress Amplitude \\
\hline$\sigma_{m}$ & Mean Stress \\
\hline$S_{u l t}$ & Ultimate tensile strength \\
\hline$\sigma_{\max }$ & Maximum stress amplitude \\
\hline$\sigma_{\min }$ & Minimum stress amplitude \\
\hline$S_{e}$ & Endurance strength \\
\hline$n$ & Factor of safety \\
\hline
\end{tabular}

\section{ABBREVIATIONS}

FEA - Finite Element Analysis

CAE - Computer Aided Engineering

NVH - Noise, Vibration \& Harshness

$\mathrm{CG}-$ Centre of Gravity

CAD - Computer Aided Design

RPM - Revolutions per Minute

UTS - Ultimate Tensile Strength 